\title{
Vitamin D Deficiency in Pediatric Critical Care
}

\author{
J. Dayre McNally ${ }^{1,2}$ Karin Amrein ${ }^{3}$ \\ ${ }^{1}$ Division of Critical Care, Department of Pediatrics, Faculty of \\ Medicine, University of Ottawa, Children's Hospital of Eastern \\ Ontario, Ottawa, Canada \\ 2 Research Institute, Children's Hospital of Eastern Ontario, \\ Ottawa, Canada \\ ${ }^{3}$ Division of Endocrinology and Metabolism, Department of Internal \\ Medicine, Medical University of Graz, Austria \\ J Pediatr Intensive Care 2016;5:142-153.
}

\begin{abstract}
Address for correspondence Dayre McNally, MSc, PhD, University of Ottawa, Pediatric Intensivist, Division of Critical Care, Children's Hospital of Eastern Ontario, 401 Smyth Road, Ottawa, Ontario, Canada, K1H 8L1 (e-mail: dmcnally@cheo.on.ca).
\end{abstract}

\begin{abstract}
Vitamin D deficiency (VDD) is a well-established cause of pediatric bone and muscle disease. In addition, a role has been recognized for vitamin $D$ in the health and stress response of other organs, including the cardiovascular, immune, and respiratory systems. As these organs are central to the development of and recovery from critical illness, VDD has been hypothesized to be a modifiable risk factor for ICU outcome. Over the past 5 years, a growing number of adult and pediatric critical care studies have investigated the prevalence of VDD and its association with illness severity and outcome. The adult studies have recently been synthesized in systematic reviews, with results that convincingly suggest the need for trials to determine whether optimization of vitamin D status improves outcome. In contrast, the pediatric ICU and related literature has not been similarly synthesized. The goal of this review is to describe vitamin D metabolism, known biological mechanisms, potential role in pathophysiology, and summarize the available pediatric intensive care unit (PICU) studies reporting on prevalence of VDD deficiency and its association with outcome. The problems with currently approved supplementation approaches and alternative

Keywords

- pediatric critical care

- endocrinology

- vitamin D strategies are discussed, including evidence from available RCTs in adult ICU. Altogether the results suggest that critically ill children are at risk for VDD, and that VDD appears to be associated with a worse clinical course. Clinical trials evaluating novel approaches to testing for and supplementing vitamin $\mathrm{D}$ require exploration.
\end{abstract}

\section{Introduction}

Severe vitamin D deficiency (VDD) is a well-established cause of pediatric disease, including hypocalcemia, skeletal abnormalities, and stunted growth. ${ }^{1-3}$ Although severe deficiency is now rare, many adults and children have subclinical VDD that does not manifest classic symptoms. Concern has been expressed about subclinical VDD as research suggests that it could predispose patients to or impair recovery from a variety of neurologic, cardiovascular, respiratory, and immune disorders. ${ }^{4-6}$ As these organs are central to the development and

received

September 30, 2015

accepted after revision

October 22, 2015

published online

May 4, 2016
Critical Care; Guest Editors: Kusum Menon, MSc, MD, and Dayre McNally, $\mathrm{MSc}, \mathrm{PhD}$

recovery from critical illness, VDD has been hypothesized to be a modifiable risk factor for worse outcomes in intensive care unit (ICU). ${ }^{7}$

Over the past 5 years there has been a rapid growth of ICU literature on vitamin D. Dozens of adult studies have convincingly demonstrated associations between VDD and illness severity, patient morbidity, and mortality. This work has culminated in book chapters, ${ }^{8}$ narrative reviews, ${ }^{9-13}$ systematic reviews, ${ }^{14-16}$ pilot clinical trials, ${ }^{17-22}$ and a phase III randomized clinical trials (RCT) suggesting safety and clinical efficacy of high-dose supplementation. ${ }^{23}$ In contrast, there

Copyright $\odot 2016$ by Georg Thieme Verlag KG, Stuttgart · New York
DOI http://dx.doi.org/ 10.1055/s-0036-1583285. ISSN 2146-4618. 
have been relatively few attempts to synthesize the pediatric literature. ${ }^{24}$ This review summarizes the pediatric intensive care unit (PICU) literature on VDD, discusses problems with approved supplementation regimens, and presents alternative strategies for evaluation as part of clinical trials.

\section{Vitamin D Deficiency}

\section{What Is Vitamin D?}

The term vitamin $D$ refers to two molecules: ergocalciferol (D2) and cholecalciferol (D3). Both forms can be attained through naturally occurring dietary sources, fortified foods, and pharmaceutical supplements. Of the two, only cholecalciferol can be synthesized in the skin from 7-dehydrocholesterol following ultraviolet (UV) irradiation. Both D2 and D3 are biologically inert, requiring two separate hydroxylations to become active. The initial hydroxylation is performed by liver cytochrome P450 enzymes (25-hydroxylases), producing the prehormone calcidiol or 25-hydroxyvitamin D (250HD). Calcidiol is the major vitamin D metabolite in the body (nanomolar blood concentrations) and circulates $99 \%$ bound to vitamin D-binding protein (VDBP) and albumin. A subsequent nonliver hydroxylation generates the active hormone called calcitriol (1,25 dihydroxyvitamin D or 1,25 $\left.(\mathrm{OH})_{2} \mathrm{D}\right)($ - Fig. 1 ).

\section{Vitamin D Parathyroid Renal Axis}

The best understood function of vitamin $D$ is the maintenance of blood and body calcium levels ${ }^{25}$ (see - Fig. 1). When blood calcium falls, the parathyroid gland is stimulated and increases parathyroid hormone (PTH) secretion. Higher PTH levels prompt the kidneys to increase hydroxylase activity converting more available calcidiol to active hormone. The active hormone is circulated in the blood to the bone, gut, and kidneys where it binds to vitamin D receptor (VDR) and translocates to the nucleus. The calcitriol:VDR complex interacts with other proteins triggering changes in transcription of hundreds of genes. These changes work to restore calcium homeostasis through increased enteral absorption, decreased renal secretion, and modulation of osteoclast and osteoblast activity.

\section{Nonclassic Functions of Vitamin D}

It is now well recognized that dozens of cells outside of the bone, intestine, and kidneys have active VDRs, including myocytes, endothelial cells, white blood cells, pancreatic islets, and skeletal muscle. ${ }^{26,27}$ Additional studies have also shown that many cells remote from the kidneys produce $\alpha$ hydroxylases and generate calcitriol from calcidiol for both autocrine and paracrine purposes. Laboratory studies involving both cell lines and animal models have convincingly demonstrated that depletion of vitamin D negatively impacts normal development and stress response. Finally, in addition to altering transcription, it is now evident that vitamin $\mathrm{D}$ has nongenomic mechanisms where it can rapidly (within minutes) alter cell functioning through signaling pathways at the plasma membrane (caveolae) or t-tubules. ${ }^{27-30}$

\section{Definition of Vitamin D Status}

Calcidiol (250HD) levels are widely regarded as the best indicator of vitamin D status. Although variability exists, 50 $\mathrm{nmol} / \mathrm{l}$ is widely used as the threshold to define deficiency, with 25 or $30 \mathrm{nmol} / \mathrm{l}$ representing severe deficiency (-Fig. 2). Some agencies also recognize an additional state of "insufficiency" with adequate or normal status achieved when levels exceed 75 or $80 \mathrm{nmol} / \mathrm{l}^{31,32}$ These thresholds are based on biochemical indicators of axis stress and values below which disease predisposition rises. In brief, when 250HD falls to 50 $\mathrm{nmol} / \mathrm{L}$, maintenance of circulating calcitriol levels requires elevation of serum PTH and increased renal hydroxylase activity. ${ }^{33,34}$ As $250 \mathrm{HD}$ falls to $30 \mathrm{nmol} / 1$ renal production of calcitriol declines and healthy individuals can develop electrolyte disturbances and clinically evident musculoskeletal pathology. ${ }^{34-36}$ These thresholds apply specifically to bone health; the $250 H D$ concentrations required for optimal nonrenal hydroxylase activity have not been defined.

\section{Explanation of the Potential Role for Vitamin $D$ in ICU Pathophysiology}

The biological mechanisms through which VDD may contribute to primary or secondary ICU pathophysiology have been presented in full elsewhere ${ }^{11,37}$; however, a few examples are discussed here.

\section{Hypocalcemia}

Hypocalcemia occurs frequently during pediatric critical illness, and both its occurrence and administration of parenteral calcium have been associated with increased morbidity and mortality. ${ }^{38-41}$ Normal intra- and extracellular calcium homeostasis is important as it initiates and propagates nerve conduction, muscle contraction, and contributes to signal transduction. In addition to adult critical care studies, pediatric work has shown that patients with low calcium are more likely to have abnormalities of the vitamin D axis, including low 250HD, hypoparathyroidism, and/or renal dysfunction. ${ }^{38,39,42}$

\section{Immune Dysfunction}

Pediatric critical illness is frequently accompanied by an intense inflammatory response. ${ }^{43,44}$ VDRs have been identified on all major immune cell types, and current evidence suggests that proper signaling through these receptors is essential for modulating the immune response. For example, vitamin $\mathrm{D}$ has been demonstrated to inhibit antigen-induced T-cell proliferation, antagonize the proinflammatory Th1 response, alter gene expression of adhesion factors, and decrease neutrophil adherence and chemotaxis. ${ }^{45-47}$ Important functions in innate immunity have also been identified. For example, activation of the VDR is important for transcription and translation of antimicrobial peptides (e.g., cathelicidin ). ${ }^{48-50}$ Cathelicidin levels have been correlated with both infectious disease outcomes and vitamin D concentrations. $^{50-52}$ Pediatric observational studies have linked 250HD levels and polymorphisms of both VDR and VDBP to various autoimmune and infectious conditions, including RSV, diabetes, and asthma exacerbations. ${ }^{53-55}$ 


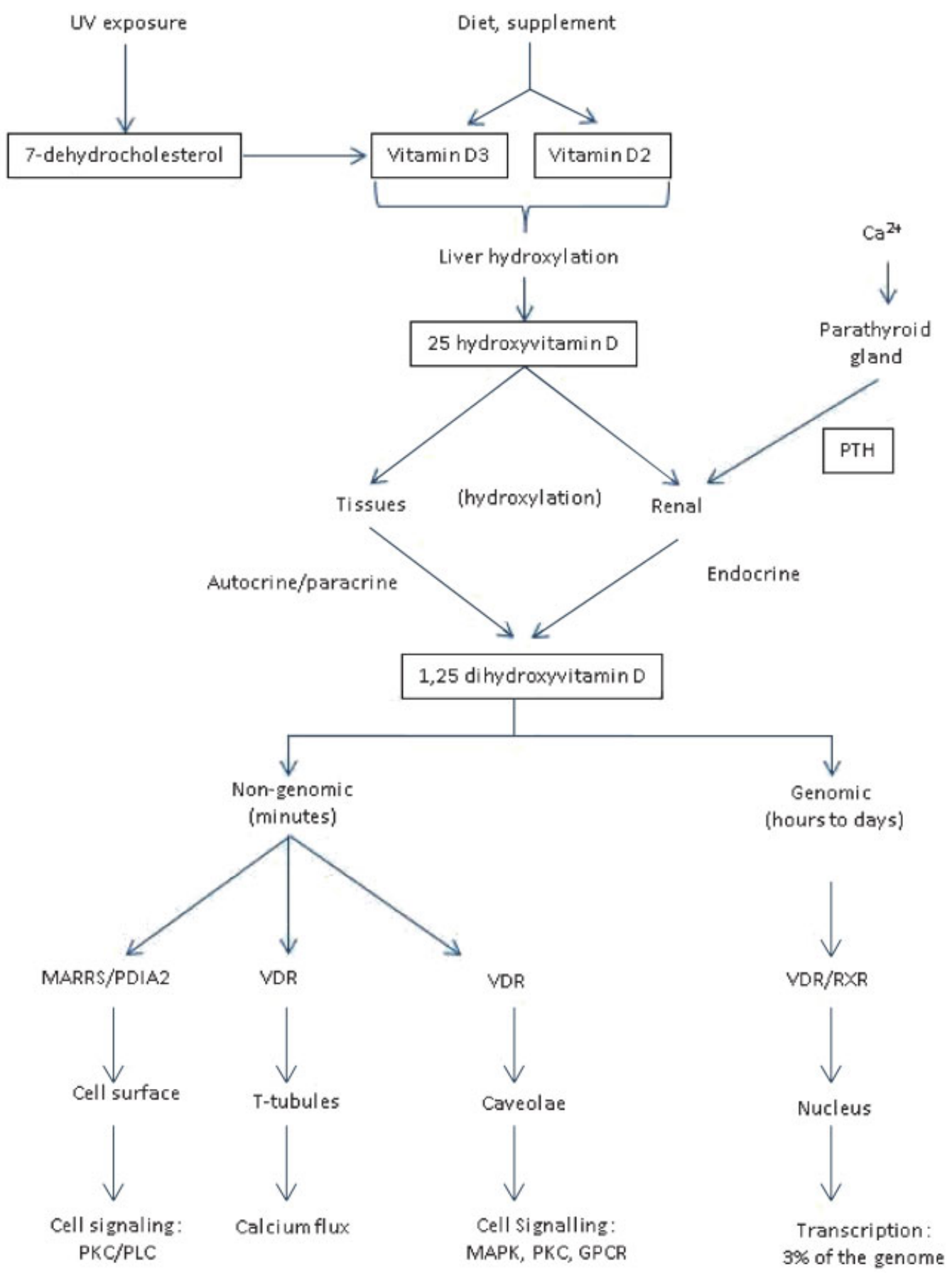

Fig. 1 Metabolism of vitamin D. Vitamin $D_{3}$ can be synthesized in human skin following exposure to ultraviolet light. Both vitamins $D_{3}$ and $D_{2}$ can also be acquired from consumption of specific foods, fortified foods, and pharmaceutical supplements. Both forms are transported to the liver where CYP450 enzymes generate the 25 hydroxyvitamin D metabolite and release it into the circulation. A second hydroxylation is required to produce the active hormone calcitriol. Circulating calcitriol is primarily produced in the kidney by an $\alpha$ hydroxylase that is regulated by parathyroid hormone (positively) and fibroblast growth factor (negatively). Multiple cells also synthesize their own hydroxylase and can locally convert 25OHD for autocrine and paracrine use. Once activated, there are multiple mechanisms through which vitamin D can alter cell function. It is well known that calcitriol binding leads to nuclear translocation of the VDR where it works with transcription factors to upregulate and downregulate transcription of genes. In addition, it has also been established that calcitriol can elicit several rapid nongenomic responses from the plasma membrane (or t-tubules) through binding to the VDR or alternative calcitriol receptors (e.g., MARRS). Abbreviations: $\mathrm{Ca}^{2+}$, ionized calcium; GPCR, G protein coupled receptor; MAPK, MAP kinase; MARRS, membraneassociated rapid-response steroid binding; PDIA3, protein disulfide isomerize family A, member 3; PKC, protein kinase C; PLA, phospholipase A; PLC, phospholipase C; PTH, parathyroid hormone; RXR, retinoid-X receptor; UV, ultraviolet; VDR, vitamin D receptor.

\section{Cardiovascular Dysfunction}

Cardiovascular dysfunction is common in PICU, with patients frequently receiving fluid and inotropes to support cardiac output. $^{56}$ In addition to indirect effects through calcium, vitamin D influences myocyte structure and function via gene and protein expression. ${ }^{26}$ Additional research has shown that myocyte contractility can be favorably altered within minutes by $1,25(\mathrm{OH})_{2} \mathrm{D}$ supplementation, mediated 
through signal transduction pathways, enzymatic reactions, and ion channels. ${ }^{28-30}$ Pediatric clinical studies support these laboratory observations, demonstrating that children with rickets frequently have subclinical cardiac dysfunction along with case reports/series suggesting cardiomyopathy secondary to severe VDD. ${ }^{57-61}$ A recent pilot RCT evaluating stable children with heart failure demonstrated improved heart function scores and echocardiographic findings with highdose vitamin $\mathrm{D}(2,000 \mathrm{IU} / \mathrm{d})$ when compared with placebo. ${ }^{62}$

\section{Muscle Weakness and Rehabilitation}

ICU-acquired weakness is a well-recognized consequence of critical illness, and contributes to mortality, morbidity, worse functional outcomes, and quality of life. ${ }^{63-66}$ A significant body of observational research on children and adults has clearly demonstrated that severe VDD can cause muscle pathology and clinically relevant weakness. ${ }^{67-71}$ Recently, studies have demonstrated potentially long-lasting effects of high-dose vitamin $\mathrm{D}$ on body lean muscle mass in infants and young children. ${ }^{72,73}$ Further, a recent RCT evaluating administration of 540,000 IU to critically ill adults demonstrated that patients with 250 HD levels between 30 and 50 $\mathrm{nmol} / \mathrm{L}$ who received study drug had improved grip strength and physical components of the SF-12. ${ }^{23}$

\section{Prevalence of Vitamin D Deficiency in PICU}

\section{Vitamin D Deficiency in PICU}

Prior to 2012, little attention was paid to vitamin D status during pediatric critical illness, with only three small studies reporting $250 H D$ levels on a total of 88 children. ${ }^{39,74,75}$ Since 2012 there have been 10 observational studies evaluating vitamin D status in general PICU populations, ${ }^{76-85}$ two focused on postoperative congenital heart disease (CHD), ${ }^{86,87}$ and a pilot study of high-dose vitamin $\mathrm{D}$ in children with burns. ${ }^{88}$ The 10 observational PICU studies originate from six countries and evaluate 2,000 children. Almost all studies were single center, collected only one blood sample (at or near admission), and evaluated vitamin D status using total $250 H D$. Further, with the exception of Rey and colleagues, ${ }^{79}$ all studies defined VDD using the $50 \mathrm{nmol} / \mathrm{L}$ threshold. As shown in - Fig. 3, prevalence of VDD ranged from 28 to $84 \%$, suggesting significant risk for VDD in the PICU. Three of the studies also sought to determine whether 250HD levels were lower in critically ill children compared with other children. Hebbar and colleagues showed statistically lower 250HD levels compared with a group of unwell children receiving care at the same hospital (99 vs. $46 \mathrm{nmol} / \mathrm{L}) .{ }^{81}$ Similarly, in their investigation of PICU patients with sepsis, Ponnarmeni et al demonstrated significantly lower 250HD levels compared with healthy controls ( $49.25 \mathrm{vs} .68 .7 \mathrm{nmol} / \mathrm{L}){ }^{85}$

In addition to studies on the general PICU populations, there have been two recent observational studies focused on children with CHD. ${ }^{86,87}$ In a secondary analysis, Graham and colleagues reported that $84 \%$ of neonates undergoing cardiac surgery had VDD postoperatively. In a prospective Canadian study, mean immediate postoperative vitamin D status was $35 \mathrm{nmol} / \mathrm{L}$ (85\% VDD). In the pilot RCT of high-dose vitamin D
(100 IU $/ \mathrm{kg}$ ) in severe pediatric burn injury, the mean 250HD concentration was $50 \mathrm{nmol} / \mathrm{L}^{88}$

\section{Change in 250HD Levels during Hospital Admission}

Available PICU literature evaluates VDD at admission but does not address how vitamin $\mathrm{D}$ status changes throughout the hospital stay. Only two of the pediatric studies evaluated 250HD levels at more than one time in the PICU. The Canada multicenter study did not observe differences in group 250HD levels between days 1 and $2,^{76}$ and the prospective longitudinal study of children undergoing CHD surgery demonstrated that 250HD levels remained stable over a 48-hour period following separation from cardiopulmonary bypass. ${ }^{86}$ Studies from related populations evaluating 250HD over a longer period provide more useful and concerning findings. In a mixed population of hospitalized children (ward/PICU) Dayal and colleagues observed a significant decline in 250HD from admission $(72 \mathrm{nmol} / \mathrm{L})$ to discharge $(49 \mathrm{nmol} / \mathrm{L}){ }^{89}$ Similar adult studies by Higgins et $\mathrm{al}^{90}$ and Yi et $\mathrm{al}^{91}$ reported a significant decline in 250HD levels over 10- and 35-day study periods, respectively. The placebo group in a phase III RCT of high-dose vitamin D in critically ill adults found no significant change in $250 \mathrm{HD}$ (mean, $35 \mathrm{nmol} / \mathrm{L}$ ) over the first 30 days. $^{23}$

\section{Vitamin D Deficiency and Critical Illness}

Similar to the general population, reduced consumption of specific foods and inadequate UV exposure (sun avoidance, sunscreen, skin melanin content, high latitude) predisposes many children to preillness VDD. It is also increasingly evident that critical illness and related interventions (surgery, fluids, extracorporeal membrane oxygenation [ECMO], cardiopulmonary bypass, plasma exchange) may significantly reduce vitamin D levels. ${ }^{86}$ Disruption of the hepatic, parathyroid and renal organ function (reducing hydroxylation) and greater tissue requirements during catabolism may also reduced 250HD. Acute changes in $250 \mathrm{HD}$ may be more harmful than chronically low levels as the endocrine axis and individual cells require time to adjust to new steady-state levels.

\section{Association of Vitamin D Status with Illness Severity and Clinical Outcome}

\section{Adult ICU Observational Studies}

Since 2009, dozens of observational studies have investigated the role of vitamin D in more than 10,000 critically ill adults. Many of these studies estimate concerning VDD rates and report associations with illness severity, organ dysfunction, complications, clinical course, and/or mortality. ${ }^{7,12-15,19,29-31}$ In 2014, two systematic reviews synthesized the available literature and calculating an almost twofold greater risk of in-hospital death in VDD. ${ }^{15,16}$ Further meta-analysis demonstrated statistically significant differences in sepsis, ${ }^{15}$ culture positive infection, ${ }^{15}$ and a descriptive analysis suggested an association with increased length of stay. ${ }^{16}$ Three large studies, linking hospital laboratory and 


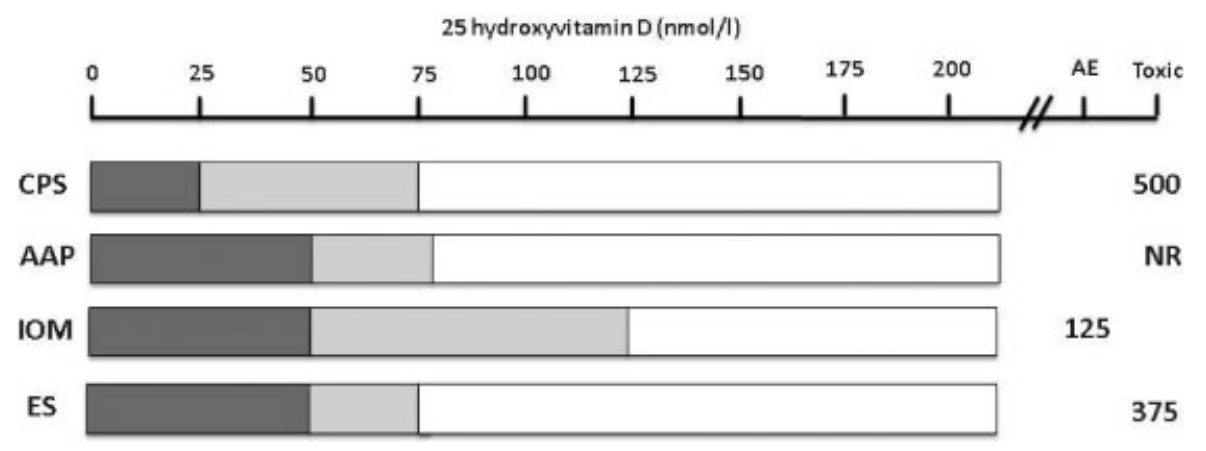

Fig. 2 Example thresholds for vitamin D status. Vitamin D thresholds suggested by various agencies and societies to define vitamin D deficiency (dark bar), vitamin D insufficiency (gray bar), and sufficiency (white bar). The 25 hydroxyvitamin D levels suggested to be associated with adverse events (AE) or toxicity are shown to the right of the bar. Abbreviations: AAP, American Academy of Pediatrics; CPS, Canadian Pediatric Society; ES, Endocrine Society; IOM, Institute of Medicine; NR, not reported.

admission data, determined preillness vitamin $\mathrm{D}$ levels to be associated with in-hospital mortality. ${ }^{92-94}$ Given the convincing quantity and quality of the observational evidence, multiple adult research groups have proceeded to clinical trials.

\section{PICU Observational Studies}

In addition to describing vitamin D status, all the general PICU studies assessed associations between 250HD and at least one marker of illness severity or clinical outcome. As shown in -Table 1, there is considerable variability in the number and type of measures reported. This lack of consistency, combined with the application of different measurement tools and considerable differences in sample size, makes it challenging to interpret and synthesize the findings. Mortality, the clinical outcome arguably of greatest importance and least subjectivity was reported in six publications. Unfortunately, no individual PICU study was sufficiently powered to investigate an association with mortality. However, it is worth noting that with the exception of the study by Rippel and colleagues, ${ }^{77}$ the five remaining studies all reported higher mortality rates in the VDD groups. With the cumulative number of children approaching 2,000, it would be worthwhile combining individual study findings as part of a systematic review and meta-analysis. Of the remaining associations investigated, the two most common included illness severity $(n=10)$ and cardiovascular support $(n=8)$. Overall, an association between illness severity and VDD is strongly suggested as four studies reported statistically significant associations and three studies calculated trends toward statistical significance. Similarly, among the eight studies evaluating cardiovascular outcomes, four reported significantly more cardiovascular support in at least one analysis and two others reported clinically meaningful differences that did not achieve statistical significance. A significant association between 250HD levels and cardiovascular support was also reported in both studies focused on postoperative CHD patients. ${ }^{86,87}$ It is worth commenting on the findings from a few specific studies. First, the lone multicenter study

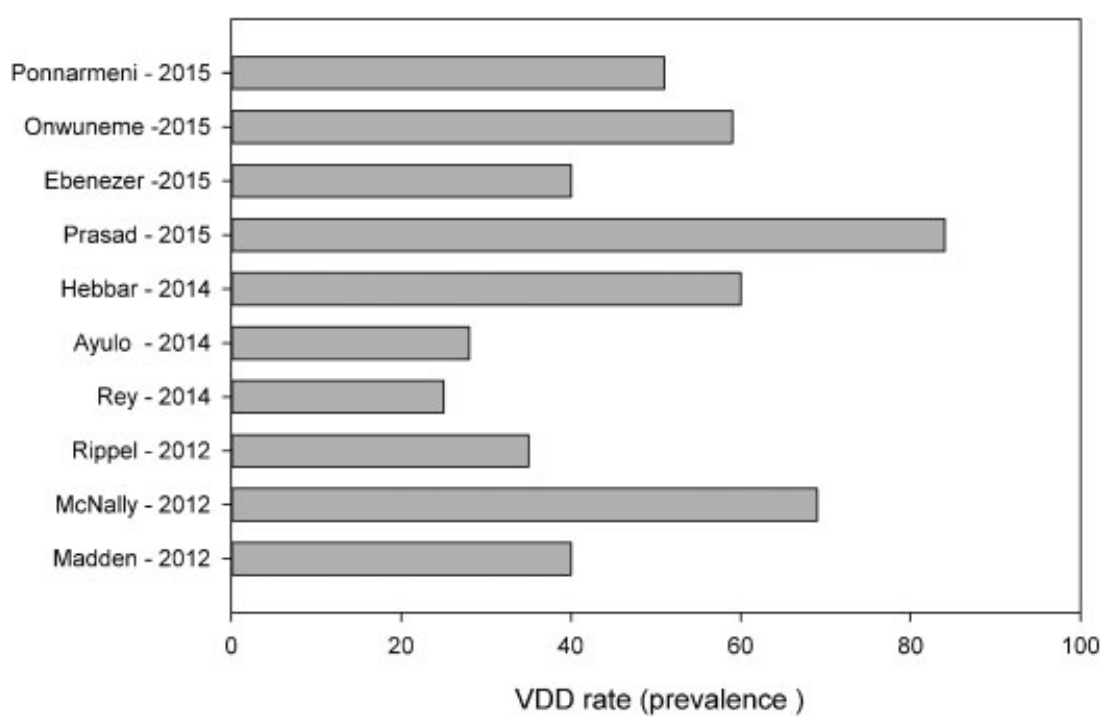

Fig. 3 Prevalence of vitamin D receptor (VDD) in PICU observational studies. This figure shows the prevalence of VDD in the 10 general PICU observational studies. With the exception of Rey and colleagues ( $37.5 \mathrm{nmol} / \mathrm{L}$ ), VDD was defined using the $50 \mathrm{nmol} / \mathrm{L}$ threshold. 


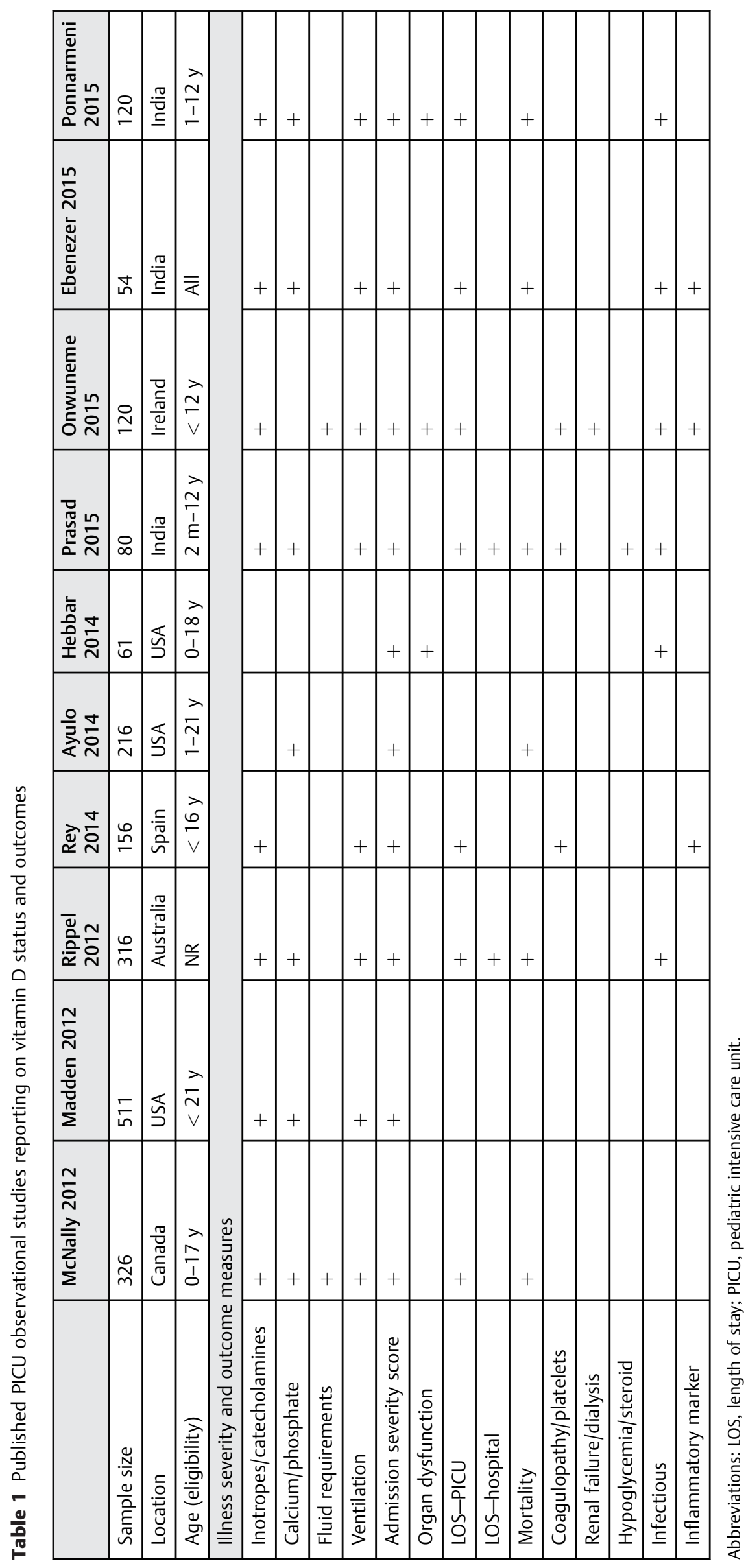


demonstrated that VDD was associated with a significantly increased length of PICU stay (2 days) after adjusting for important covariates including PRISM (Pediatric Risk of Mortality Score). ${ }^{76}$ Second, an Irish study focused on PICU patients with sepsis and the authors reported significantly higher rates of culture proven sepsis in the VDD group. ${ }^{83}$ Finally, although the cumulative evidence supports a role for VDD in PICU, it cannot be overlooked that two moderately sized studies failed to find associations with most clinical outcome measures. ${ }^{77,85}$ Based on existing work, it would appear that a large multicenter study enrolling a thousand patients, and correcting for important confounders, would be required to further solidify the relationship between $250 \mathrm{HD}$ levels and clinical course. As this observational study would still leave the more important question unanswered, it might be more appropriate to use the resources for a large multicenter interventional.

\section{Approved Vitamin D Supplementation Regimens}

\section{Usual Care}

Because of the known negative health consequences of VDD, it is recommended that children intake a minimum quantity of vitamin $\mathrm{D}$. The recommended daily allowance (RDA) or adequate intake (AI) suggested by the Institute of Medicine (IOM) and supported by Health Canada are 400 IU for infants and $600 \mathrm{IU}$ for older children. ${ }^{95}$ Slightly higher doses have been suggested by the Canadian Pediatric Society (CPS) for infants living in Northern Canada (800 IU). ${ }^{96}$ Presently, no standard of care for vitamin D supplementation has been established during or following pediatric critical illness. If ordered at all, a daily dose of vitamin D between 400 and 800 IU is provided enterally or with total parenteral nutrition, but it is well recognized that these doses can take 2 or more months to restore vitamin D status in stable, otherwise healthy children. ${ }^{73,97}$ As previously discussed, available evidence on hospitalized and critically ill patients suggests that vitamin D levels generally remain constant or fall over time with usual care. ${ }^{89,90}$ As this approach leaves critically ill patients in a VDD state over an extended period, alternative dosing regimens need consideration.

\section{Approved High-Dose Regimens}

In addition to RDA, the IOM provides a higher age-specific dose called the tolerable upper intake level(UL), which ranges from 1,000 to 4,000 IU. $^{95}$ When given daily, this dose is intended to gradually elevate vitamin $\mathrm{D}$ into the high normal range, while safely avoiding toxicity. The UL provided by the IOM was based on evidence from healthy children, and serves as a starting point for research on high-risk populations. A recent systematic review of pediatric clinical trials evaluated dosing in the 1,000 to 4,000 IU range, demonstrating that most patients would not achieve normal levels until after a month of treatment. ${ }^{98}$ Further concerning, this systematic review also determined that children who are unwell may have a blunted 250HD response suggesting that normalization of vitamin D status in deficient critically ill patients using a daily dosing approach may be even slower. A recent pilot RCT evaluating a regimen of $800 \mathrm{IU}+100 \mathrm{IU} / \mathrm{kg}$ in pediatric burn patients confirmed these concerns showing that half of the patients remained VDD at the projected midpoint of their hospital admission. ${ }^{88}$ Altogether, it appears that approved high-dose daily regimens will not restore vitamin $\mathrm{D}$ status in a time frame beneficial for the critically ill child.

\section{Alternative Vitamin D Supplementation Strategies}

\section{Loading Dose Vitamin D (Stoss Therapy)}

The supplementation strategy most appropriate for the ICU setting is loading dose (or Stoss therapy) where 40,000 to $600,000 \mathrm{IU}$ are provided as single or divided doses. A recent systematic review sought to understand 250HD response to loading dose therapy in children. ${ }^{98}$ Although dozens of studies administering loading dose therapy were identified, none included critically ill children. Evaluation of the change in levels of 250HD demonstrated that vitamin D levels can be normalized within 48 hours, but that weight-based dosing was necessary to avoid both under- and overdosing. Ultimately, $10,000 \mathrm{IU} / \mathrm{kg}$ was proposed as the dose for consideration in future trials.

Trials of High-Dose Vitamin D in Related Populations There is some clinical trial evidence to suggest that loading therapy may improve outcomes in related non-PICU populations. Primary among the evidence is VITdAL-ICU trial, where 540,000 IU (enteral) and placebo were compared in critically ill adults. Although there was no difference in length of stay (primary objective), there was a clinically meaningful difference in mortality (43 vs. $35 \%, p=0.09$ ). ${ }^{23}$ Further subgroup analysis suggested an interaction between outcome and baseline 25(OH)D level, as (1) participants with baseline 25 $(\mathrm{OH}) \mathrm{D}$ under $30 \mathrm{nmol} / \mathrm{L}$ had a statistically significant mortality reduction ( $50 \mathrm{vs.} 35 \%, p=0.02$ ), and (2) participants with baseline $25(\mathrm{OH}) \mathrm{D}$ between 30 and $50 \mathrm{nmol} / \mathrm{L}$ showing improved grip strength and physical components of the SF-12 questionnaire. Two pediatric studies evaluating loading dose therapy in ill populations have also suggested benefit. First, an RCT of 450 young children presenting with acute lower respiratory tract infection demonstrated that a 100,000-IU enteral dose reduced repeat episodes. ${ }^{99}$ Second, a recent systematic review of pediatric clinical trials of vitamin D in asthma demonstrated that high-dose vitamin D supplementation, including a 60,000-IU monthly loading regimen, reduced asthma exacerbations by $50 \%{ }^{100,101}$

\section{Safety of High-Dose Vitamin D}

As an inexpensive and simple intervention, it would be understandable for PICUs to consider overlooking the lack of high-quality clinical trial evidence and begin implementation of high-dose therapy. Preventing this are the concerns spawned from case reports, case series, and a small number of clinical trials establishing that inappropriate vitamin D intake, resulting in supraphysiological 250HD 
levels, can cause toxicity. ${ }^{102,103}$ Vitamin D toxicity is characterized by hypercalcemia or hypercalciuria, with the classic symptoms (lethargy, abdominal pain, anorexia, constipation, polyuria, and nocturia) directly attributable to these abnormalities. With prolonged states of hypercalcemia and hypercalciuria, children are at risk for developing nephrocalcinosis and other renal pathology. However, there is considerable evidence to suggest that loading dose therapy, designed with the goal of achieving normal vitamin D levels, will be safe. First, studies in healthy children receiving regimens approximating the UL did not demonstrate toxicity with cumulative dosing approximating $10,000 \mathrm{IU} / \mathrm{kg} .^{73,97,104}$ Second, a review of pediatric nephrocalcinosis studies identified that cases attributed to vitamin D occur in the context of one or more doses of greater than 600,000 IU administered to healthy children or those with genetic abnormalities of VDR. ${ }^{105-109}$ Third, an adverse event analysis performed as part of a systematic review of high-dose pediatric trials did not find evidence of toxicity until dosing exceeded 400,000 IU. Fourth, the VITdAL-ICU study did not demonstrate increased hypercalcemia, hypercalciuria, or nephrocalcinosis in the group of vitamin D-deficient critically ill adults that received 540,000 IU. $^{23}$ Fifth, pediatric case reports and case series of clinical and subclinical cardiac dysfunction secondary to VDD describe improvements in patient status with both gradual and rapid restoration of vitamin D levels. ${ }^{57-61,110}$ Finally, pediatric RCTs evaluating loading dose therapy in healthy and stable unwell pediatric populations (e.g., pneumonia, asthma) have not suggested safety con- cerns. ${ }^{99-101,111}$ Altogether, these findings strongly suggest that rapid normalization of vitamin D status in critically ill children could have more benefit than harm, but further study is necessary to confirm this.

\section{Controversies and Knowledge Gaps}

\section{Are There Better Markers for Vitamin D Status for ICU?}

Given the high incidence of hepatic, renal, and parathyroid organ dysfunction, it has been suggested that calcitriol might represent a superior marker of vitamin D status in critically ill patients. Two adult studies have been published to date evaluating this question, with neither showing calcitriol to be superior or additive to calcidiol in the relationship with illness severity or clinical outcome. ${ }^{112,113}$ A large pediatric study published in 2015 further demonstrated that although associations with interventions and clinical course were evident, they disappeared once $250 \mathrm{HD}$ was considered. ${ }^{114}$ More recently, groups have suggested that bioavailable 250HD might be a better measure, given alterations in VDBP and albumin levels during critical illness. The limited adult and pediatric work in this area have not demonstrated total 25OHD to be inferior, ${ }^{112,115}$ but further study is warranted.

\section{Uncertainty Surrounding the Best Dosing Regimen}

To date, seven pilot and one phase III trials have been published in various adult ICU settings (-Table 2). With the exception of the pilot performed prior to the phase III VITdAL-ICU, none of studies used the same combination of

Table 2 Vitamin D dosing regimens considered to date as part of clinical trials in ICU

\begin{tabular}{|c|c|c|c|c|c|c|c|c|}
\hline & Population & $n$ & Metabolite & Dose & Frequency & Route & $\begin{array}{l}\text { Usual } \\
\text { care arm }\end{array}$ & Comment \\
\hline \multicolumn{9}{|l|}{ Pediatric-pilot } \\
\hline Gottschlish, 2015 & Burns & 18 & Ergocalciferol & $100 \mathrm{IU} / \mathrm{kg}$ & Daily & $\mathrm{PO}$ & Yes & \\
\hline Gottschlish, 2015 & Burns & 15 & Cholecalciferol & $100 \mathrm{IU} / \mathrm{kg}$ & Daily & $\mathrm{PO}$ & Yes & \\
\hline \multicolumn{9}{|l|}{ Adult-pilot } \\
\hline Ingels, 2010 & General & 11 & Calcidiol & $\begin{array}{l}8,000 \mathrm{IU} \text { load, } \\
600 \mathrm{IU} / \mathrm{d}\end{array}$ & $10 \mathrm{~d}$ & IV & Yes & Abstract only \\
\hline Mata-Granados, 2010 & Sepsis & 11 & Calcidiol & $60,000 \mathrm{IU}$ & Days: 0,4 & $\mathrm{PO}$ & Yes & Non-RCT \\
\hline Mata-Granados, 2010 & Sepsis & 10 & Calcitriol & $2.0 \mathrm{mcg}$ & Days: $0,2,4,6$ & IV & Yes & \\
\hline Amrein, 2011 & General, VDD & 10 & Cholecalciferol & $540,000 \mathrm{IU}$ & Once & $\mathrm{PO}$ & Yes & \\
\hline Leaf, 2014 & Severe sepsis & 36 & Calcitriol & $2.0 \mu \mathrm{g}$ & Once & IV & Yes & \\
\hline Nair, 2015 & Sepsis/SIRS & 25 & Cholecalciferol & $150,000 \mathrm{IU}$ & Once & $\mathrm{IM}$ & No & \\
\hline Nair, 2015 & Sepsis/SIRS & 25 & Cholecalciferol & $300,000 \mathrm{IU}$ & Once & $\mathrm{IM}$ & No & \\
\hline Dickerson, 2015 & Trauma & 16 & Ergocalciferol & $50,000 \mathrm{IU}$ & Once weekly & $\mathrm{PO}$ & No & \\
\hline Dickerson, 2015 & Trauma & 18 & Ergocalciferol & $50,000 \mathrm{IU}$ & Twice weekly & $\mathrm{PO}$ & No & \\
\hline Dickerson, 2015 & Trauma & 31 & Ergocalciferol & $50,000 \mathrm{IU}$ & Thrice weekly & $\mathrm{PO}$ & No & \\
\hline Rousseau, 2015 & Burn & 13 & Cholecalciferol & $200,000 \mathrm{IU}$ & Q3m & $\mathrm{IM}$ & Yes & \\
\hline Amrein, 2014 & General & 249 & Cholecalciferol & $\begin{array}{l}540,000 \mathrm{IU} \\
\text { then } 90,000 \mathrm{IU}\end{array}$ & Once & $\begin{array}{l}\text { Once }+ \\
\text { per month }\end{array}$ & Yes & Phase III RCT \\
\hline
\end{tabular}

Abbreviations: ICU, intensive care unit; IM, intramuscular; IV, intravenous; PO, oral; RCT, randomized clinical trial; SIRS, systemic inflammatory response syndrome; VDD, vitamin D deficiency. 
metabolite, dose, frequency, and route. Demonstrating the variability, the metabolites selected in nonplacebo arms included cholecalciferol $(n=5)$, ergocalciferol $(n=3)$, calcidiol $(n=2)$, and calcitriol $(n=2)$. Within the D3 and D2 arms, there were five doses (50,000-540,000 IU) and four frequency options. Importantly, roughly half of the arms utilized intramuscular administration, which has the disadvantage of a longer time to reach peak effect and lower final 250HD concentration. Although calcidiol is a reasonable option for supplementation, there are valid arguments against the use of calcitriol, the active hormone: (1) increased expense relative to cholecalciferol, (2) knowledge that calcitriol levels do not correlate better with clinical outcome, and (3) observations that loading therapy with D3 or 25OHD results in a rapid rise in calcitriol (two to three fold). Finally, the suggestive results of the VITdAL-ICU trial support further evaluation of enteral loading dose cholecalciferol, but given that many ICU patients cannot receive enteral medications for prolonged periods, it would be reasonable to also explore an IV preparation of cholecalciferol or 250HD.

\section{Potential Impact and Next Steps}

Critical illness occurs in millions of children worldwide every year. In addition to death, these children are at risk for significant morbidity due to organ dysfunction, prolonged periods of rehabilitation, and chronic disease. Given the potential importance of vitamin $D$ to the health and stress response of multiple organ systems, the high VDD rate reported in many ICUs should be of concern. Cumulative observational and clinical trial data suggest that rapid normalization of vitamin D status could represent a simple, inexpensive, and safe means of improving outcomes and reducing health care spending. Unfortunately many of the approved daily dosing regimens for vitamin $\mathrm{D}$ can require months to restore levels. Loading therapy represents a more appropriate approach for restoring vitamin D status in critically ill children. Unfortunately, there have been no studies of loading therapy in the PICU setting. Consequently, despite significant literature suggesting VDD to be a modifiable risk factor in critical illness, there is no robust evidence to inform us on how to rapidly normalize levels or the true benefits or risks. RCTs including dose-evaluation pilots and phase III RCTs will be required.

\section{Funding}

None.

Conflict of interest

None.

\section{References}

1 Ward LM, Gaboury I, Ladhani M, Zlotkin S. Vitamin D-deficiency rickets among children in Canada. CMAJ 2007;177(2):161-166
2 Mehrotra P, Marwaha RK, Aneja S, et al. Hypovitaminosis d and hypocalcemic seizures in infancy. Indian Pediatr 2010;47(7): 581-586

3 Basatemur E, Sutcliffe A. Incidence of hypocalcemic seizures due to vitamin D deficiency in children in the United Kingdom and Ireland. J Clin Endocrinol Metab 2015;100(1):E91-E95

4 Ginde AA, Mansbach JM, Camargo CA Jr. Vitamin D, respiratory infections, and asthma. [Review] [53 refs]Curr Allergy Asthma Rep 2009;9(1):81-87

5 Kim SY. The pleiomorphic actions of vitamin D and its importance for children. Ann Pediatr Endocrinol Metab 2013;18(2):45-54

6 Zittermann A, Gummert JF. Nonclassical vitamin D action. Nutrients 2010;2(4):408-425

7 Lee P, Nair P, Eisman JA, Center JR. Vitamin D deficiency in the intensive care unit: an invisible accomplice to morbidity and mortality? Intensive Care Med 2009;35(12):2028-2032

8 Youssef D, Amrein K, Schnedl C, Dobnig H, Peiris AN. Intensive Care and Vitamin D status. Diet and Nutrition in Critical Care. Vol 1. New York, NY: Springer; 2014:16

9 Amrein K, Venkatesh B. Vitamin D and the critically ill patient. Curr Opin Clin Nutr Metab Care 2012;15(2):188-193

10 Christopher KB. Vitamin D supplementation in the ICU patient. Curr Opin Clin Nutr Metab Care 2015;18(2):187-192

11 Lee P. Vitamin D metabolism and deficiency in critical illness. Best Pract Res Clin Endocrinol Metab 2011;25(5):769-781

12 Amrein K, Christopher KB, McNally JD. Understanding vitamin D deficiency in intensive care patients. Intensive Care Med 2015; 41(11):1961-1964

13 Williams S, Heuberger R. Outcomes of vitamin D supplementation in adults who are deficient and critically ill: a review of the literature. Am J Ther 2015

14 Zajic P, Amrein K. Vitamin D deficiency in the ICU: a systematic review. Minerva Endocrinol 2014;39(4):275-287

15 de Haan K, Groeneveld AB, de Geus HR, Egal M, Struijs A. Vitamin $D$ deficiency as a risk factor for infection, sepsis and mortality in the critically ill: systematic review and meta-analysis. Crit Care 2014;18(6):660

16 Zhang YP, Wan YD, Sun TW, Kan QC, Wang LX. Association between vitamin D deficiency and mortality in critically ill adult patients: a meta-analysis of cohort studies. Crit Care 2014;18(6):684

17 Amrein K, Sourij H, Wagner G, et al. Short-term effects of highdose oral vitamin D3 in critically ill vitamin D deficient patients: a randomized, double-blind, placebo-controlled pilot study. Crit Care 2011;15(2):R104-R104

18 Mata-Granados JM, Vargas-Vasserot J, Ferreiro-Vera C, Luque de Castro MD, Pavón RG, Quesada Gómez JM. Evaluation of vitamin D endocrine system (VDES) status and response to treatment of patients in intensive care units (ICUs) using an on-line SPE-LCMS/MS method. J Steroid Biochem Mol Biol 2010;121(1-2): 452-455

19 Nair P, Venkatesh B, Lee P, et al. A randomized study of a single dose of intramuscular cholecalciferol in critically ill adults. Crit Care Med 2015;43(11):2313-2320

20 Dickerson RN, Berry SC, Ziebarth JD, et al. Dose-response effect of ergocalciferol therapy on serum 25-hydroxyvitamin D concentration during critical illness. Nutrition 2015;31(10):1219-1223

21 Leaf DE, Raed A, Donnino MW, Ginde AA, Waikar SS. Randomized controlled trial of calcitriol in severe sepsis. Am J Respir Crit Care Med 2014;190(5):533-541

22 Aminmansour B, Nikbakht $\mathrm{H}$, Ghorbani A, et al. Comparison of the administration of progesterone versus progesterone and vitamin $\mathrm{D}$ in improvement of outcomes in patients with traumatic brain injury: a randomized clinical trial with placebo group. Adv Biomed Res 2012;1:58

23 Amrein K, Schnedl C, Holl A, et al. Effect of high-dose vitamin D3 on hospital length of stay in critically ill patients with vitamin $\mathrm{D}$ deficiency: the VITdAL-ICU randomized clinical trial.JAMA 2014; 312(15):1520-1530 
24 Abou-Zahr R, Kandil SB. A pediatric critical care perspective on vitamin D. Pediatr Res 2015;77(1-2):164-167

25 Shoback D. Clinical practice. Hypoparathyroidism. N Engl J Med 2008;359(4):391-403

26 Nibbelink KA, Tishkoff DX, Hershey SD, Rahman A, Simpson RU. 1,25( $\mathrm{OH}) 2$-vitamin D3 actions on cell proliferation, size, gene expression, and receptor localization, in the HL-1 cardiac myocyte. J Steroid Biochem Mol Biol 2007;103(3-5):533-537

27 Haussler MR, Jurutka PW, Mizwicki M, Norman AW. Vitamin D receptor (VDR)-mediated actions of $1 \alpha, 25(\mathrm{OH})_{2}$ vitamin $\mathrm{D}_{3}$ : genomic and non-genomic mechanisms. Best Pract Res Clin Endocrinol Metab 2011;25(4):543-559

28 Green JJ, Robinson DA, Wilson GE, Simpson RU, Westfall MV. Calcitriol modulation of cardiac contractile performance via protein kinase C. J Mol Cell Cardiol 2006;41(2):350-359

29 Santillán GE, Vazquez G, Boland RL. Activation of a beta-adrenergic-sensitive signal transduction pathway by the secosteroid hormone 1,25-(OH)2-vitamin D3 in chick heart. J Mol Cell Cardiol 1999;31(5):1095-1104

30 Tishkoff DX, Nibbelink KA, Holmberg KH, Dandu L, Simpson RU. Functional vitamin D receptor (VDR) in the t-tubules of cardiac myocytes: VDR knockout cardiomyocyte contractility. Endocrinology 2008;149(2):558-564

31 Holick MF, Binkley NC, Bischoff-Ferrari HA, et al; Endocrine Society. Evaluation, treatment, and prevention of vitamin D deficiency: an Endocrine Society clinical practice guideline. J Clin Endocrinol Metab 2011;96(7):1911-1930

32 Wagner CL, Greer FR; American Academy of Pediatrics Section on Breastfeeding; American Academy of Pediatrics Committee on Nutrition. Prevention of rickets and vitamin D deficiency in infants, children, and adolescents. Pediatrics 2008;122(5):1142-1152

33 Willett AM. Vitamin D status and its relationship with parathyroid hormone and bone mineral status in older adolescents. Proc Nutr Soc 2005;64(2):193-203

34 Christensen MH, Lien EA, Hustad S, Almås B. Seasonal and agerelated differences in serum 25-hydroxyvitamin D, 1,25-dihydroxyvitamin D and parathyroid hormone in patients from Western Norway. Scand J Clin Lab Invest 2010;70(4):281-286

35 Docio S, Riancho JA, Pérez A, Olmos JM, Amado JA, GonzálezMacías J. Seasonal deficiency of vitamin $D$ in children: a potential target for osteoporosis-preventing strategies? J Bone Miner Res 1998;13(4):544-548

36 Thacher TD, Fischer PR, Isichei CO, Pettifor JM. Early response to vitamin D2 in children with calcium deficiency rickets. J Pediatr 2006;149(6):840-844

37 Lee P, Eisman JA, Center JR. Vitamin D deficiency in critically ill patients. N Engl J Med 2009;360(18):1912-1914

38 Cardenas-Rivero N, Chernow B, Stoiko MA, Nussbaum SR, Todres ID. Hypocalcemia in critically ill children. J Pediatr 1989;114(6): 946-951

39 Gauthier B, Trachtman H, Di Carmine F, et al. Hypocalcemia and hypercalcitoninemia in critically ill children. Crit Care Med 1990; 18(11):1215-1219

40 Iqbal M, Rehmani R, Hijazi M, Abdulaziz A, Kashif S. Hypocalcemia in a Saudi intensive care unit. Ann Thorac Med 2008;3(2): 57-59

41 Dyke PC II, Yates AR, Cua CL, et al. Increased calcium supplementation is associated with morbidity and mortality in the infant postoperative cardiac patient. Pediatr Crit Care Med 2007;8(3): 254-257

42 Broner CW, Stidham GL, Westenkirchner DF, Tolley EA. Hypermagnesemia and hypocalcemia as predictors of high mortality in critically ill pediatric patients. Crit Care Med 1990;18(9): 921-928

43 Kozik DJ, Tweddell JS. Characterizing the inflammatory response to cardiopulmonary bypass in children. Ann Thorac Surg 2006; 81(6):S2347-S2354
44 Jaggers J, Lawson JH. Coagulopathy and inflammation in neonatal heart surgery: mechanisms and strategies. Ann Thorac Surg 2006;81(6):S2360-S2366

45 Baeke F, Gysemans C, Korf H, Mathieu C. Vitamin D insufficiency: implications for the immune system. Pediatr Nephrol 2010; 25(9):1597-1606

46 Rigby WF, Denome S, Fanger MW. Regulation of lymphokine production and human $\mathrm{T}$ lymphocyte activation by 1,25-dihydroxyvitamin D3. Specific inhibition at the level of messenger RNA. J Clin Invest 1987;79(6):1659-1664

47 Bhalla AK, Amento EP, Serog B, Glimcher LH. 1,25-Dihydroxyvitamin D3 inhibits antigen-induced T cell activation. J Immunol 1984;133(4):1748-1754

48 Hata TR, Kotol P, Jackson M, et al. Administration of oral vitamin D induces cathelicidin production in atopic individuals. J Allergy Clin Immunol 2008;122(4):829-831

49 Gombart AF, Borregaard N, Koeffler HP. Human cathelicidin antimicrobial peptide (CAMP) gene is a direct target of the vitamin $\mathrm{D}$ receptor and is strongly up-regulated in myeloid cells by 1,25-dihydroxyvitamin D3. FASEB J 2005;19(9):1067-1077

50 Jeng L, Yamshchikov AV, Judd SE, et al. Alterations in vitamin D status and anti-microbial peptide levels in patients in the intensive care unit with sepsis. J Transl Med 2009;7:28-28

51 Gombart AF, Bhan I, Borregaard N, et al. Low plasma level of cathelicidin antimicrobial peptide (hCAP18) predicts increased infectious disease mortality in patients undergoing hemodialysis. Clin Infect Dis 2009;48(4):418-424

52 Leaf DE, Croy HE, Abrahams SJ, Raed A, Waikar SS. Cathelicidin antimicrobial protein, vitamin D, and risk of death in critically ill patients. Crit Care 2015;19:80

53 McNally JD, Sampson M, Matheson LA, Hutton B, Little J. Vitamin $D$ receptor (VDR) polymorphisms and severe RSV bronchiolitis: a systematic review and meta-analysis. Pediatr Pulmonol 2014; 49(8):790-799

54 Brehm JM, Schuemann B, Fuhlbrigge AL, et al; Childhood Asthma Management Program Research Group. Serum vitamin D levels and severe asthma exacerbations in the Childhood Asthma Management Program study. J Allergy Clin Immunol 2010;126(1):52-8.e5

55 Maxwell CS, Carbone ET, Wood RJ. Better newborn vitamin D status lowers RSV-associated bronchiolitis in infants. Nutr Rev 2012;70(9):548-552

56 Menon K, Ward RE, Lawson ML, Gaboury I, Hutchison JS, Hébert PC; Canadian Critical Care Trials Group. A prospective multicenter study of adrenal function in critically ill children. Am J Respir Crit Care Med 2010;182(2):246-251

57 Olgun H, Ceviz N, Ozkan B. A case of dilated cardiomyopathy due to nutritional vitamin D deficiency rickets. Turk J Pediatr 2003; 45(2):152-154

58 Price DI, Stanford LC Jr, Braden DS, Ebeid MR, Smith JC. Hypocalcemic rickets: an unusual cause of dilated cardiomyopathy. Pediatr Cardiol 2003;24(5):510-512

59 Verma S, Khadwal A, Chopra K, Rohit M, Singhi S. Hypocalcemia nutritional rickets: a curable cause of dilated cardiomyopathy. J Trop Pediatr 2011;57(2):126-128

60 Maiya S, Sullivan I, Allgrove J, et al. Hypocalcaemia and vitamin D deficiency: an important, but preventable, cause of life-threatening infant heart failure. Heart 2008;94(5):581-584

61 Uysal S, Kalayci AG, Baysal K. Cardiac functions in children with vitamin D deficiency rickets. Pediatr Cardiol 1999;20(4):283-286

62 Shedeed SA. Vitamin D supplementation in infants with chronic congestive heart failure. Pediatr Cardiol 2012;33(5):713-719

63 Banwell BL, Mildner RJ, Hassall AC, Becker LE, Vajsar J, Shemie SD. Muscle weakness in critically ill children. Neurology 2003; 61(12):1779-1782

64 Williams S, Horrocks IA, Ouvrier RA, Gillis J, Ryan MM. Critical illness polyneuropathy and myopathy in pediatric intensive care: a review. Pediatr Crit Care Med 2007;8(1):18-22 
65 Kress JP, Hall JB. ICU-acquired weakness and recovery from critical illness. N Engl J Med 2014;370(17):1626-1635

66 Batt J, dos Santos CC, Cameron JI, Herridge MS. Intensive care unit-acquired weakness: clinical phenotypes and molecular mechanisms. Am J Respir Crit Care Med 2013;187(3):238-246

67 Al-Said YA, Al-Rached HS, Al-Qahtani HA, Jan MMS. Severe proximal myopathy with remarkable recovery after vitamin $D$ treatment. Can J Neurol Sci 2009;36(3):336-339

68 Al-Said YA, Al-Rached HS, Al-Qahtani HA, Jan MM. Severe proximal myopathy with remarkable recovery after vitamin $D$ treatment. Can J Neurol Sci 2009;36(3):336-339

69 Ward KA, Das G, Berry JL, et al. Vitamin D status and muscle function in post-menarchal adolescent girls. J Clin Endocrinol Metab 2009;94(2):559-563

70 van der Heyden JJ, Verrips A, ter Laak HJ, Otten B, Fiselier T. Hypovitaminosis D-related myopathy in immigrant teenagers. Neuropediatrics 2004;35(5):290-292

71 Torun E, Genç H, Gönüllü E, Akovalı B, Ozgen IT. The clinical and biochemical presentation of vitamin D deficiency and insufficiency in children and adolescents. J Pediatr Endocrinol Metab 2013;26(5-6):469-475

72 Hazell TJ, Gallo S, Berzina I, Vanstone CA, Rodd C, Weiler HA. Plasma 25-hydroxyvitamin D, more so than its epimer, has a linear relationship to leaner body composition across infancy in healthy term infants. Appl Physiol Nutr Metab 2014;39(10): 1137-1143

73 Gallo S, Comeau K, Vanstone C, et al. Effect of different dosages of oral vitamin D supplementation on vitamin D status in healthy, breastfed infants: a randomized trial. JAMA 2013;309(17): 1785-1792

74 McNally JD, Leis K, Matheson LA, Karuananyake C, Sankaran K, Rosenberg AM. Vitamin D deficiency in young children with severe acute lower respiratory infection. Pediatr Pulmonol 2009;44(10):981-988

75 Gottschlich MM, Mayes T, Khoury J, Warden GD. Hypovitaminosis $D$ in acutely injured pediatric burn patients. J Am Diet Assoc 2004; 104(6):931-941, quiz 1031

76 McNally JD, Menon K, Chakraborty P, et al; Canadian Critical Care Trials Group. The association of vitamin D status with pediatric critical illness. Pediatrics 2012;130(3):429-436

77 Rippel C, South M, Butt WW, Shekerdemian LS. Vitamin D status in critically ill children. Intensive Care Med 2012;38(12): 2055-2062

78 Madden K, Feldman HA, Smith EM, et al. Vitamin D deficiency in critically ill children. Pediatrics 2012;130(3):421-428

79 Rey C, Sánchez-Arango D, López-Herce J, et al. Vitamin D deficiency at pediatric intensive care admission. J Pediatr (Rio J) 2014; 90(2):135-142(Versão em Português)

80 Ayulo M Jr, Katyal Ch, Agarwal Ch, et al. The prevalence of vitamin D deficiency and its relationship with disease severity in an urban pediatric critical care unit. Endocr Regul 2014;48(2):69-76

81 Hebbar KB, Wittkamp M, Alvarez JA, McCracken CE, Tangpricha V, Vitamin D. Vitamin D deficiency in pediatric critical illness. J Clin Transl Endocrinol 2014;1(4):170-175

82 Prasad S, Raj D, Warsi S, Chowdhary S, Vitamin D. Vitamin D deficiency and critical illness. Indian J Pediatr 2015;82(11):991-995

83 Onwuneme C, Carroll A, Doherty D, et al. Inadequate vitamin D levels are associated with culture positive sepsis and poor outcomes in paediatric intensive care. Acta Paediatr 2015;104(10): e433-e438

84 Ebenezer K, Job V, Antonisamy B, Dawodu A, Manivachagan MN, Steinhoff M. Serum vitamin D status and outcome among critically ill children admitted to the pediatric intensive care unit in South India. Indian J Pediatr 2015

85 Ponnarmeni S, Kumar Angurana S, Singhi S, et al. Vitamin D deficiency in critically ill children with sepsis. Paediatr Int Child Health 2016;36(1):15-21
86 McNally JD, Menon K, Chakraborty P, et al. Impact of anesthesia and surgery for congenital heart disease on the vitamin d status of infants and children: a prospective longitudinal study. Anesthesiology 2013;119(1):71-80

87 Graham EM, Taylor SN, Zyblewski SC, et al. Vitamin D status in neonates undergoing cardiac operations: relationship to cardiopulmonary bypass and association with outcomes. J Pediatr 2013; 162(4):823-826

88 Gottschlich MM, Mayes T, Khoury J, Kagan RJ. Clinical Trial of Vitamin D2 vs D3 Supplementation in Critically Ill Pediatric Burn Patients. JPEN J Parenter Enteral Nutr 2015

89 Dayal D, Kumar S, Sachdeva N, Kumar R, Singh M, Singhi S. Fall in vitamin D levels during hospitalization in children. Int J Pediatr 2014;2014:291856

90 Higgins DM, Wischmeyer PE, Queensland KM, Sillau SH, Sufit AJ, Heyland DK. Relationship of vitamin D deficiency to clinical outcomes in critically ill patients. JPEN J Parenter Enteral Nutr 2012;36(6):713-720

91 Yi HJ, Jeong JH, Jin ES, Shin IY, Hwang HS, Moon SM. Evaluation of vitamin D level in patients from neurosurgical intensive care unit. Neural Regen Res 2013;8(16):1528-1534

92 Lange N, Litonjua AA, Gibbons FK, Giovannucci E, Christopher KB. Pre-hospital vitamin D concentration, mortality, and bloodstream infection in a hospitalized patient population. Am J Med 2013;126(7):640.e19-640.e27

93 Amrein K, Litonjua AA, Moromizato T, et al. Increases in prehospitalization serum $25(\mathrm{OH}) \mathrm{D}$ concentrations are associated with improved 30-day mortality after hospital admission: A cohort study. Clin Nutr 2015

94 Braun A, Chang D, Mahadevappa K, et al. Association of low serum 25-hydroxyvitamin D levels and mortality in the critically ill. Crit Care Med 2011;39(4):671-677

95 Ross AC, Manson JE, Abrams SA, et al. The 2011 report on dietary reference intakes for calcium and vitamin $D$ from the Institute of Medicine: what clinicians need to know. J Clin Endocrinol Metab 2011;96(1):53-58

96 Godel JC. Vitamin D supplementation: recommendations for Canadian mothers and infants. Paediatr Child Health (Oxford) 2007;12(7):583-598

97 Holmlund-Suila E, Viljakainen H, Hytinantti T, Lamberg-Allardt C, Andersson S, Mäkitie O. High-dose vitamin d intervention in infants-effects on vitamin d status, calcium homeostasis, and bone strength. J Clin Endocrinol Metab 2012;97(11): 4139-4147

98 McNally JD, Iliriani K, Pojsupap S, et al. Rapid normalization of vitamin D levels: a meta-analysis. Pediatrics 2015;135(1): e152-e166

99 Manaseki-Holland S, Qader G, Isaq Masher M, et al. Effects of vitamin D supplementation to children diagnosed with pneumonia in Kabul: a randomised controlled trial. Trop Med Int Health 2010;15(10):1148-1155

100 Pojsupap S, Iliriani K, Sampaio TZ, et al. Efficacy of high-dose vitamin $\mathrm{D}$ in pediatric asthma: a systematic review and metaanalysis. . J Asthma 2014:1-9

101 Yadav M, Mittal K. Effect of vitamin D supplementation on moderate to severe bronchial asthma. Indian J Pediatr 2014; 81(7):650-654

102 Joshi R. Hypercalcemia due to hypervitaminosis D: report of seven patients. J Trop Pediatr 2009;55(6):396-398

103 Markestad T, Hesse V, Siebenhuner M, et al. Intermittent highdose vitamin D prophylaxis during infancy: effect on vitamin D metabolites, calcium, and phosphorus. Am J Clin Nutr 1987; 46(4):652-658

104 Lewis RD, Laing EM, Hill Gallant KM, et al. A randomized trial of vitamin $\mathrm{D}_{3}$ supplementation in children: dose-response effects on vitamin D metabolites and calcium absorption. J Clin Endocrinol Metab 2013;98(12):4816-4825 
105 Ammenti A, Pelizzoni A, Cecconi M, Molinari PP, Montini G. Nephrocalcinosis in children: a retrospective multi-centre study. Acta Paediatr 2009;98(10):1628-1631

106 Rönnefarth G, Misselwitz J. Nephrocalcinosis in children: a retrospective survey. Members of the Arbeitsgemeinschaft für pädiatrische Nephrologie. Pediatr Nephrol 2000;14(10-11):1016-1021

107 Moncrieff MW, Chance GW. Nephrotoxic effect of vitamin D therapy in vitamin D refractory rickets. Arch Dis Child 1969; 44(237):571-579

108 Mantan M, Bagga A, Virdi VS, Menon S, Hari P. Etiology of nephrocalcinosis in northern Indian children. Pediatr Nephrol 2007;22(6):829-833

109 Alon US. Nephrocalcinosis. Curr Opin Pediatr 1997;9(2):160-165

110 Kosecik M, Ertas T. Dilated cardiomyopathy due to nutritional vitamin D deficiency rickets. Pediatr Int 2007;49(3): 397-399

111 Manaseki-Holland S, Maroof Z, Bruce J, et al. Effect on the incidence of pneumonia of vitamin $\mathrm{D}$ supplementation by quar- terly bolus dose to infants in Kabul: a randomised controlled superiority trial. Lancet 2012;379(9824):1419-1427

112 Quraishi SA, Bittner EA, Blum L, McCarthy CM, Bhan I, Camargo CA Jr. Prospective study of vitamin D status at initiation of care in critically ill surgical patients and risk of 90-day mortality. Crit Care Med 2014;42(6):1365-1371

113 Nair P, Lee P, Reynolds C, et al. Significant perturbation of vitamin D-parathyroid-calcium axis and adverse clinical outcomes in critically ill patients. Intensive Care Med 2013;39(2): 267-274

114 Dayre McNally J, Menon K, Lawson ML, Williams K, Doherty DR. 1,25 dihydroxyvitamin $D$ levels in pediatric intensive care units: risk factors and association with clinical course. J Clin Endocrinol Metab 2015;100(8):2942-5

115 Madden K, Feldman HA, Chun RF, et al. Critically ill children have low vitamin d-binding protein, influencing bioavailability of vitamin D. Ann Am Thorac Soc 2015; 12(11):1654-1661 